\title{
Abrasive Wear Behavior of Heat-Treated ABC-Silicon Carbide
}

\author{
Xiao Feng Zhang ${ }^{1}$, Gun Y. Lee ${ }^{2}$, Da Chen ${ }^{4 \sharp}$, \\ R. O. Ritchie ${ }^{1,3}$, Lutgard C. De Jonghe ${ }^{1,3}$ \\ ${ }^{1}$ Materials Sciences Division, Lawrence Berkeley National Laboratory, \\ University of California, Berkeley, CA 94720, USA \\ ${ }^{2}$ Department of Mechanical Engineering, University of California, Berkeley, CA 94720, USA \\ ${ }^{3}$ Department of Materials Science \& Engineering, University of California, Berkeley, CA 94720, USA \\ ${ }^{4}$ Department of Materials Science \& Engineering, Shanghai Jiao Tong University, Shanghai 200030,
} China

\begin{abstract}
Hot-pressed silicon carbide, containing aluminum, boron, and carbon additives (ABC-SiC), was subjected to three-body and two-body wear testing using diamond abrasives over a range of sizes. In general, the wear resistance of ABC-SiC, with suitable heat treatment, was superior to that of commercial SiC. With the fine-scale $(3 \mu \mathrm{m})$ diamond abrasives, it was found that thermal annealing at $1300^{\circ} \mathrm{C}$ increased the resistance to three-body wear by a factor of almost three, and two-body wear by a factor of almost two, compared to as-hot-pressed samples. Higher annealing temperatures, however, led to a decline in wear resistance from its highest value. Similar behavior was seen for $1300^{\circ} \mathrm{C}$ annealed samples subjected to $15 \mu \mathrm{m}$ diamond abrasive, although higher-temperature annealing at $1500^{\circ}-1600^{\circ} \mathrm{C}$ enhanced the wear resistance again. With coarse abrasives $(72$ $\mu \mathrm{m})$, the wear resistance progressively increased with increasing annealing temperature from $\sim 1000$ to $1600^{\circ} \mathrm{C}$. Corresponding transmission and scanning electron microscopy studies indicated that whereas transgranular, conchoidal cracking was dominant in the mild abrasive wear with fine-scale $(3 \mu \mathrm{m})$ abrasives, intergranular cracking and subsequent grain pullout was far more predominant in the more severe abrasive wear with coarse abrasives. Because the hardness and indentation toughness were barely altered during thermal treatment, the observed wear behavior is attributed mainly to the thermallyinduced microstructural changes, including the crystallization of the glassy grain-boundary films, the possible strengthening of the boundaries due to the enhance of the $\mathrm{Al}$, and the formation of Al-rich, coherent nanoscale precipitates in the matrix grains above $1300^{\circ} \mathrm{C}$.
\end{abstract}

Keywords: SiC, Annealing, Wear resistance, Precipitate, Fracture, Microstructure.

\footnotetext{
deceased.
} 


\section{LBNL-50783}

\section{Introduction}

The application of high-performance ceramics at elevated temperatures requires not only a high degree of chemical stability, but also excellent resistance to structural deformation, fracture, wear and erosion. Enhanced strength, hardness, toughness, and creep resistance are critical importance for components proposed for use in gas turbines, piston engines, heat exchangers and aerospace applications, as well. Exceptional hardness and wear resistance are also desired for ceramic materials used in brake linings, electrical contacts, and high-speed and high-precision cutting tools.

Among the various classes of high-temperature structural ceramics, hot-pressed, monolithic silicon carbide ( $\mathrm{SiC}$ ) may be one of the most attractive. Recent efforts have led to the successful in situ toughening of hot-pressed $\mathrm{SiC}$, containing $\mathrm{Al}, \mathrm{B}$, and $\mathrm{C}$, (ABC$\mathrm{SiC})$, where large-crack fracture toughness $K_{I C}$ values as high as $9.1 \mathrm{MPa} \mathrm{m}^{1 / 2}$ have been achieved, ${ }^{1-3}$ i.e., approaching that of self-reinforced $\mathrm{Si}_{3} \mathrm{~N}_{4}{ }^{4}$ This is to be compared with commercial $\mathrm{SiC}$ ceramics where $K_{I C}$ values are characteristically less than $5 \mathrm{MPa} \mathrm{m}^{1 / 2}$. This remarkable increase in toughness was attributed to resistance-curve behavior from grain bridging in the crack wake induced by the structural evolution of the grain-boundary films. Whereas grain boundaries in polycrystalline ceramics often contain a thin layer of amorphous material, ${ }^{5-9}$ extensive transmission electron microscopy (TEM) characterization revealed that the grain-boundary films in the hot-pressed ABC-SiC could be crystallized during heat treatment. ${ }^{9}$ High-resolution TEM also detected the presence of Al-rich nanoscale precipitates formed above $\sim 1300^{\circ} \mathrm{C}$ during post-annealing heat treatments..$^{10,11}$ These changes in microstructure may be expected to affect the wear resistance of ABC$\mathrm{SiC}$.

The object of this paper is to study the effect of post hot-pressing heat treatments on the abrasive wear behavior of the hot-pressed monolithic ABC-SiC. It is found that the wear resistance of $\mathrm{ABC}-\mathrm{SiC}$ is quite sensitive to annealing treatments above $1000^{\circ} \mathrm{C}$, and can be almost tripled by annealing at $1300^{\circ} \mathrm{C}$ to exceed that of a commercial silicon carbide (Hexoloy SA). 


\section{LBNL-50783}

\section{Experimental Procedures}

\section{(1) Materials Preparation}

Dense $\mathrm{SiC}$ was prepared by hot-pressing submicron $\beta$-SiC powders (H. C. Starck, Germany) mixed with $3 \mathrm{wt} \% \mathrm{Al}$ (metal) ${ }^{1}, 0.6 \mathrm{wt} \% \mathrm{~B}^{2}$, and $2 \mathrm{wt} \% \mathrm{C}$. Carbon was introduced as Apiezon wax $^{3}$ dissolved in toluene, and the other powders were then added to the suspension which was subsequently agitated with an ultrasonic probe for 10 minutes to minimize agglomerate formation. The resulting slurry was stir dried, and the material was ground in a mortar and pestle prior to sieving through a 200 mesh screen.

The green samples were pre-compacted with a $35 \mathrm{MPa}$ die pressure. For hot pressing, three samples were inserted into a graphite die lined with graphite foil. Graphite spacers were placed between each of the three samples. The hot-press furnace was heated in vacuo to $\sim 400^{\circ} \mathrm{C}$ overnight, and then brought to the hot-pressing temperature of $1900{ }^{\circ} \mathrm{C}$ at a rate of $10^{\circ} \mathrm{C} / \mathrm{min}$. A load of $50 \mathrm{MPa}$, a hot pressing time of $1 \mathrm{hr}$, and flowing argon gas were used. After hot pressing, the furnace was naturally cooled down to room temperature. The hot-pressed products consisted of $4 \mathrm{~mm}$ thick discs, $38 \mathrm{~mm}$ in diameter, with a density of $3.18 \mathrm{~g} / \mathrm{mm}^{3}$. One surface of the discs was polished to a $1 \mu \mathrm{m}$ finish prior to the samples being sectioned for mechanical testing and characterization using scanning and transmission electron microscopy.

Individual specimens were post-annealed for $72 \mathrm{hr}$, in argon at a series of temperatures, in $100^{\circ} \mathrm{C}$ intervals, between 1000 and $1600^{\circ} \mathrm{C}$. All post-annealing treatments, wear tests, and structural characterizations were performed on separate beams sectioned from the same as-hot-pressed disc.

\section{(2) Abrasive Wear Testing}

Two different configurations (tribosystems) were used for the three-body and the twobody abrasive wear testing. The first of these involved three-body, wheel-on-disk abrasive

\footnotetext{
${ }^{1} \sim 5 \mu$ m diameter powder, $\mathrm{H}-3$ and H-10, from Valimet, Stockton, CA

2 Boron powder from Callery Chemical Co, Callery, PA

${ }^{3}$ AVO Biddle Instruments, Blue Bell, PA
} 


\section{LBNL-50783}

wear, as shown schematically in Fig. 1a. Specifically, a $3 \mathrm{~mm}$ wide, $15 \mathrm{~mm}$ diameter stainless steel wheel was run at constant rotational speed and contacted onto immobile $4 \times$ $3 \times 3 \mathrm{~mm} \mathrm{SiC}$ plate-shaped samples, immersed in a slurry of 3 to $15 \mu \mathrm{m}$ diameter diamond particles suspended in water. The second wear setup allowed for two-body, pin-on-wheel abrasive wear testing, in which cross-sectional surface of a $15 \times 3 \times 3 \mathrm{~mm} \mathrm{SiC}$ beam was brought into contact with the surface of a diamond-abrasive wheel, Fig. 1b. The wheel, of diameter $150 \mathrm{~mm}$, was dressed with diamond coatings containing either 3,15 or $72 \mu \mathrm{m}$ diameter diamond particles (National Diamond Laboratory, dressing sticks: NDL stick + MDS 38$)^{4}$. All wear experiments were performed in air, at ambient temperature.

Fig. 1: Schematic illustrations of the tribological setups for (a) the three-, and (b) the two-body wear tests.

Wear was characterized by the specific wear rate, $K_{\mathrm{w}}$, defined in units of $\mathrm{mm}^{3} / \mathrm{N}$.m as the volume of material removed per unit sliding distance per unit load:

$$
K_{w}=\frac{V_{w}}{P . S}
$$

where $V_{\mathrm{w}}$ is the worn volume of the sample, $P$ is the applied normal load, and $S$ is the sliding distance. Based on this relationship, the wear resistance is defines as $1 / K_{\mathrm{w}}$.

For the three-body wear experiments (Fig. 1a), the contact load $P$ was $1 \mathrm{~N}$, over a distance $S$ of 11,000 $\mathrm{m}$ at a sliding speed of $1 \mathrm{~m} / \mathrm{s}$. For the two-body wear experiments (Fig. 1b), the contact load was $P=2 \mathrm{~N}$, over a distance of $S=1,005 \mathrm{~m}$ at a sliding speed of $0.15 \mathrm{~m} / \mathrm{s}$.

The temperature increase on the contact surface was negligible owing to the relatively low sliding speeds and high thermal conductivity of the $\mathrm{SiC}$ (e.g., $126 \mathrm{~W} /(\mathrm{m} . \mathrm{K})$ for commercial SiC Hexoloy SA). The value of the wearing volume, $V_{\mathrm{w}}$, was computed from the $\mathrm{SiC}$ density and the weight loss, the latter being measured with a microbalance to a precision of $0.001 \mathrm{~g}$. It should be noted here that the wear rate of identical samples can vary considerably when tribosystems and conditions are different. ${ }^{12}$ Accordingly, while relative trends may be compared, any quantitative comparison of the relative wear rates for

\footnotetext{
${ }^{4}$ National Diamond Lab, 4650 Alger Street, Los Angeles, CA
} 


\section{LBNL-50783}

these two types of wear testing configurations is not very meaningful; for quantitative comparison, identical facilities and conditions must be employed.

Note that Eq. (1) is fully applicable to the pin-on-wheel wear test (Fig. 1b) in which both of the contacted surfaces can be regarded as locally flat. In the wheel-on-disk wear test (Fig. 1a), the wear surface is concave, resulting in a non-uniform wear rate, such that the normal surface stress is distributed to maintain conformity with the wheel. In this case, a more appropriate definition for the specific wear rate would be to use the wear depth, $\delta_{\mathrm{w}}$, per unit sliding distance per unit normal stress, such that the wear rate, $K_{\mathrm{w}}(\sigma)$, would be given by:

$$
K_{w}^{\prime}=\frac{\delta_{w}}{\sigma S}=\frac{\dot{\delta}_{w}}{\sigma v_{w}},
$$

where $\dot{\delta}_{w}$ is the depth of the wear per unit time, $\sigma$ is the contact stress (normal load per unit area) and $v_{\mathrm{w}}$ is the sliding velocity. However, such subtleties are not explicitly addressed in this work.

\section{(3) Mechanical Properties}

The room-temperature hardness, (indentation) fracture toughness and modulus of rupture were obtained for all samples. A MICROMET microhardness tester was used for hardness measurements. A low indentation load of $4.9 \mathrm{~N}(500 \mathrm{~g})$ and an indenter dwell time of $15 \mathrm{sec}$ were applied to the $1-\mu \mathrm{m}$ polished surfaces to control the indent-to-grain size ratio; a typical diagonal across of the indents was $\sim 19 \mu \mathrm{m}$, i.e., spanning several grains. A standard Vickers indentation with a load of $78.4 \mathrm{~N}(8 \mathrm{Kg})$ was used for the indentation toughness measurements, again on the polished surfaces. Typical indent diagonals in this case were 70 to $80 \mu \mathrm{m}$, with roughly $100 \mu \mathrm{m}$ of crack extension from the indent corners. Mean toughness values and their standard deviations were determined from 30 to 40 indents.

The room-temperature moduli of rupture were determined using unnotched, $20 \times 3 \times 3$ $\mathrm{mm}$ beams, loading in four-point bending using a high-density graphite bending rig. The outer and inner loading spans were, respectively, 25.4 and $9.5 \mathrm{~mm}$, and the test was 


\section{LBNL-50783}

conducted at a cross-head speed of $0.05 \mathrm{~mm} / \mathrm{min}$. Modulus of rupture values were obtained for both the as-hot-pressed and thermally annealed samples.

\section{(4) Electron Microscopy Characterization}

To examine the microstructures using transmission electron microscopy (TEM), $3 \mathrm{~mm}$ diameter discs were cut from the $\mathrm{SiC}$ specimens, ground, dimpled and polished, before being ion-milled in an Ar-ion beam to achieve electron transparency. TEM characterization was performed at National Center for Electron Microscopy at the Lawrence Berkeley National Laboratory, using a Philips CM200 transmission electron microscope operating at $200 \mathrm{kV}$.

The topography and structure of the worn surfaces were imaged with a JSM-6340F scanning electron microscope working at $5 \mathrm{kV}$. For the preparation of cross-sectional samples for scanning electron microscopy (SEM) studies, samples were cut along a plane perpendicular to the wear surfaces. The effect of possible cutting damage was minimized by removing a few micrometers from the cut surfaces by polishing. Fig. 2 shows a scanning electron micrograph of a cross section prior to wear, indicating that the sectioning and polishing does not introduce significant near-surface damage. The two pieces were then put together again, as schematically illustrated in Fig. 3. This method is similar to that reported by Lawn et al., who used a thin layer of adhesive to bond the two pieces together. ${ }^{13}$ The surfaces were then subjected to three-body wear testing under the same conditions as described above, but for a sliding distance of $60 \mathrm{~m}$ with the direction of wear aligned along the joining line which was centered in the middle of the wear track (Fig. 3). The worn surface was then cleaned in acetone, ethanol, and baked at $150{ }^{\circ} \mathrm{C}$ for $10 \mathrm{~min}$, prior to plasma etching for SEM observation.

Fig. 2: Cross-sectional SEM micrograph showing the original surface prior to wear, indicating that the sectioning and polishing does not introduce significant near-surface damage.

Fig. 3: Schematic illustration of the procedure employed in preparation of cross-sectional SEM samples to study subsurface wear damage.

\section{Results}




\section{LBNL-50783}

\section{(1) Mechanical Properties and Wear Resistance}

Vickers indentation hardness, indentation fracture toughness, and flexural strength values for the $\mathrm{SiC}$ samples before and after thermal annealing between $800^{\circ}$ and $1600^{\circ} \mathrm{C}$ are listed in Table 1, and plotted in Fig. 4. It is apparent that whereas the hardness and indentation toughness are essentially unchanged by the annealing heat treatment, a marked increase is seen in flexure strength above $\sim 1200{ }^{\circ} \mathrm{C}$.

The wear resistance $\left(1 / K_{\mathrm{w}}\right)$ was similarly determined for as-hot-pressed and thermally annealed $\mathrm{SiC}$ samples; results from both three-body and two-body wear tests using a $3 \mu \mathrm{m}$ diamond abrasive are plotted in Fig. 5. For comparison, wear data are also shown for commercial SiC (Hexoloy SA), which was tested under identical conditions.

Fig. 4: Experimentally measured variation in indentation hardness, indentation toughness $\left(K_{I C}\right)$, and flexural strength $\left(\sigma_{\mathrm{f}}\right)$ of ABC-SiC samples as a function of the annealing temperature between $800^{\circ} \mathrm{C}$ and $1600^{\circ} \mathrm{C}$.

Fig. 5: Experimentally measured variation in three-body and two-body wear resistance $\left(1 / K_{\mathrm{w}}\right)$ as a function of the annealing temperature, using a $3 \mu \mathrm{m}$ diamond abrasive.

It is evident from Fig. 5 that the wear resistance of $\mathrm{ABC}-\mathrm{SiC}$ is affected by thermal annealing. Moreover, in most heat-treated conditions, it is superior to that of the commercial Hexoloy material. For $3 \mu \mathrm{m}$ diamond abrasive (Fig. 5), both three-body and two-body wear tests showed a continuously improving wear resistance with increasing annealing temperature until $1300{ }^{\circ} \mathrm{C}$. After such annealing, the three-body wear resistance was almost three times, and two-body wear resistance almost twice, the value for the ashot-pressed (unannealed) material. However, upon annealing at temperatures higher than $1300{ }^{\circ} \mathrm{C}$, the wear resistance appeared to decline.

These trends, however, varied significantly with the size of the diamond abrasive. Corresponding curves of wear resistance as a function of the annealing temperature are shown in Fig. 6 and Fig. 7 for the 15 and $72 \mu \mathrm{m}$ abrasives, respectively. It is apparent that similar local maxima in the wear resistance values following annealing at $\sim 1300{ }^{\circ} \mathrm{C}$ were also evident with the $15 \mu \mathrm{m}$ diamond abrasive (Fig. 6), although the peaks were not as pronounced as with the $3 \mu \mathrm{m}$ abrasive. Moreover, the wear resistance started to increase again on annealing above $\sim 1400{ }^{\circ} \mathrm{C}$. For the coarsest $72 \mu \mathrm{m}$ abrasive (Fig. 7), where only 


\section{LBNL-50783}

two-body wear was characterized, the wear resistance started to rise after annealing above $\sim 1000{ }^{\circ} \mathrm{C}$ and increased progressively with rising annealing temperature up to $1600{ }^{\circ} \mathrm{C}$, the maximum annealing temperature studied.

Fig. 6: Experimentally measured variation in three-body and two-body wear resistance $\left(1 / K_{\mathrm{w}}\right)$ as a function of the annealing temperature, using a $15 \mu \mathrm{m}$ diamond abrasive..

Fig. 7: Experimentally measured variation in two-body wear resistance $\left(1 / K_{\mathrm{w}}\right)$ as a function of the annealing temperature, using a $72 \mu \mathrm{m}$ diamond abrasive.

\section{(2) Microstructure Characterization}

The as-hot-pressed $\mathrm{ABC}-\mathrm{SiC}$ consisted of both elongated and equiaxed $\mathrm{SiC}$ grains, with 0.8-3 nm thick films of glassy phases at the grain boundaries. An SEM image of a polished and plasma etched surface, prior to the wear tests, is shown in Fig 8. The typical size for the equiaxed grains was less than $1 \mu \mathrm{m}$, while the length and width for anisotropic grains ranged, respectively, from 3 to $11 \mu \mathrm{m}$ and 1 to $3 \mu \mathrm{m}$, with an aspect ratio for $90 \%$ of the elongated $\mathrm{SiC}$ grains between 2 and 5. Both X-ray and electron diffraction previously identified the $\alpha-4 \mathrm{H}$ and $\alpha-6 \mathrm{H}$ hexagonal $\mathrm{SiC}$ phases as the dominant polytypes and various Al-rich secondary phases existed in all samples studied. ${ }^{9,14}$

Fig. 8: Scanning electron micrograph of the plasma-etched, as-hot-pressed microstructure of ABC-SiC.

As noted earlier, the thermal annealing treatment was found to result in several important microstructural changes. Crystallization of the grain-boundary films occurs after approximately an hour at temperatures above $1000{ }^{\circ} \mathrm{C}$. Fig. 9a shows a typical amorphous intergranular film formed in as-hot-pressed ABC-SiC. Systematic TEM analyses indicated that the intergranular films were composed of Al-Si-O-C. ${ }^{9}$ However, on annealing at $1000^{\circ} \mathrm{C}$ and above, the amorphous intergranular films were observed to crystallize (Fig. 9b). High-resolution electron microscopy and chemical microanalysis of the crystallized intergranular films identified one of the crystalline structures within the films as consistent with a $2 \mathrm{H}$-wurtzite structure with an aluminosilicate composition, i.e., a solid solution 


\section{LBNL-50783}

between $\mathrm{Al}_{2} \mathrm{OC}$ and $\mathrm{SiC}{ }^{9}$ In addition, the precipitation of nanoscale aluminum-containing phases was found to occur, quite rapidly, above $\sim 1300^{\circ} \mathrm{C}$ (Fig. 10); their size, shape, spacing and volume fraction are listed in Table 2. The precipitates were coherent and typically plate-shaped. No such nano-precipitates were observed in samples annealed at or below $1200^{\circ} \mathrm{C}$. For a $72 \mathrm{hr}$ thermal anneal at $1300^{\circ} \mathrm{C}$, approximately one-half to one-third of the aluminum dissolved in the SiC lattice was found to have precipitated out; indeed, isochronal annealing at $1400^{\circ} \mathrm{C}$ and above led to the complete precipitation of all the dissolved aluminum. At the same time, aluminum was observed to accumulate in the grain boundaries, with the consequent formation of a precipitate-denuded zone of low aluminum concentration adjacent to the boundaries. Chemical analysis detected a 50-100 at\% increase in $\mathrm{Al}$ content in the grain-boundary films after annealing at and above $1300{ }^{\circ} \mathrm{C}$. The width of this denuded zone was found to increase with temperature. Concurrently, the aluminum-containing precipitates in the matrix were seen to coarsen at constant overall grain-bulk composition, as shown in Fig. 10 and in Table 2. A detailed TEM study on such nano-precipitation is given in refs. [10,11].

Fig. 9: TEM micrographs showing the transformation of the amorphous grain boundary film (a) to a crystallized film (b) after thermal annealing at $1000^{\circ} \mathrm{C}$ for $5 \mathrm{hrs}$. The grain boundaries shown in (a) and (b) are not the same one.

Fig. 10: TEM micrographs showing in-grain nano-precipitates in $\mathrm{SiC}$ annealed at 1300, 1400, 1500, and $1600^{\circ} \mathrm{C}$, respectively. Note the coarsening in size accompanied by number reduction of the precipitates with increasing annealing temperature.

Table 2 summarizes the statistical values for the precipitates formed at different annealing temperatures. The typical length and thickness for the precipitates produced in the $1300{ }^{\circ} \mathrm{C}$-annealed samples are between 3 and $5 \mathrm{~nm}$, and about $1 \mathrm{~nm}$, respectively. The minimum separation is about $2 \mathrm{~nm}$. The average volume of the individual precipitates is about $16 \mathrm{~nm}^{3}$, and a number density of about $5 \times 10^{22} / \mathrm{m}^{3}$ was determined. It is apparent that isochronal annealing between $1400^{\circ}$ and $1600^{\circ} \mathrm{C}$ coarsened the precipitates significantly.

\section{(3) Characterization of the Worn Surfaces}




\section{LBNL-50783}

Considering first the fine-scale abrasives, high-magnification SEM images, obtained from the as-hot-pressed ABC-SiC, are shown in Fig. 11. The SiC surface after two-body wear with $3 \mu \mathrm{m}$ diamond abrasive can be seen. Several features can be discerned, most prominently the occurrence of polishing wear and the presence of pits resulting from the break-out of individual or groups of grains. An example of such a pit involving grainboundary failure has been highlighted in Fig. 11a. Close-ups of the light-contrast features associated with many of the pits are also shown in Figs. $11 \mathrm{~b}$ and $11 \mathrm{c}$ and can be seen to consist of transgranular, conchoidal fracture surfaces. Similar features have been found in wear and contact fatigue studies of glasses ${ }^{15}$ and other ceramics. ${ }^{16}$

Fig. 11: SEM images of the morphologies of the worn surfaces after the two-body abrasive wear with $3 \mu \mathrm{m}$ diamond abrasives, showing (a) an overall image and high magnification details of the light-contrast pits (b, c) which demonstrate transgranular, conchoidal fracture. The images were obtained from an as-hot-pressed sample.

The SEM micrographs in Fig. 12a and 12b compare plane-view images of the worn surfaces after the two-body wear tests with $3 \mu \mathrm{m}$ diamond abrasive for as-hot-pressed and $1300^{\circ} \mathrm{C}$ annealed samples. Polishing features are again common on the worn surfaces, together with dark-contrast pits due to grain break-out. One striking difference between the samples is that the grain break-out and the conchoidal fractures (light-contrast pits) are significantly reduced following thermal annealing. At a minimum, the reduction of grain break-out lowers the normal stress for the remaining, load-bearing surface. The wear surface of the annealed sample in Fig 12b shows that the light-contrast conchoidal fracture features in this sample are localized in a $15-20 \mu \mathrm{m}$ wide band in the wear direction, suggesting that these features are associated with wear damage that is caused by debris released by the sample.

Fig. 12: SEM images showing the morphologies of the worn surfaces after the two-body abrasive wear with $3 \mu \mathrm{m}$ diamond abrasives, showing (a) as-hot-pressed $\mathrm{ABC}-\mathrm{SiC}$, and (b) following $1300^{\circ} \mathrm{C}$ annealing, showing reduction in pitting due to the annealing.

Corresponding worn surfaces due to coarse-scale abrasive are shown in Fig. 13a and Fig. 13b in the form of SEM plane-view images after two-body wear tests with $72 \mu \mathrm{m}$ diamond abrasive. Unlike behavior with fine-scale abrasive (Fig. 12), the worn surfaces 


\section{LBNL-50783}

for the as-hot-pressed and $1300^{\circ} \mathrm{C}$-annealed $\mathrm{SiC}$ samples were quite similar. It can be seen that polishing-type features are no longer present, and the surface features indicate a combination of intergranular (some are marked by arrows) and transgranular fractures.

Fig. 13: SEM images showing the morphologies of the worn surfaces after the two-body abrasive wear with $72 \mu \mathrm{m}$ diamond abrasives. The image in (a) was obtained from the as-hot-pressed ABC-SiC, and that in (b) was from the sample after $1300^{\circ} \mathrm{C}$ annealing.

Thus, whereas wear with fine-scale abrasive appears to involve predominately local trangranular fracture processes, with coarse abrasive both intergranular and transgranular processes are in evidence. However, cross-sectional SEM observations indicated that all worn samples show some degree of near-surface fractures, and intergranular cracking can also be seen with three-body wear with $3 \mu \mathrm{m}$ abrasives (Fig. 14). However, the incidence of such near-surface intergranular cracking is increased with increasing abrasive size. For example, Fig. 15 shows the corresponding near-surface damage and fractures after threebody wear with $15 \mu \mathrm{m}$ abrasives. This image shows that the fracture path initially involves grain boundaries and then proceeds transgranularly.

Possible sequences of events are schematically illustrated in Fig. 16 for such creation of the wear debris under fine abrasive and coarse abrasive conditions. For mild wear with fine abrasives (Fig. 16a), micro-ploughing and (predominantly) transgranular near-surface crack formation appear to be the source of the wear debris. With coarse abrasives (Fig. $16 \mathrm{~b}$ ), the more severe and deeper damage can result in the break-out of the grain fragments as a result of continued distress from the incompatibility of intergranular cracks at triple junctions under intensive sliding by the abrasive medium. The degree of such distress is enhanced with the larger abrasive size, as shown by the cross-sectional SEM images in Fig. 17 for three-body wear of a $800{ }^{\circ} \mathrm{C}$-annealed sample with $15 \mu \mathrm{m}$ abrasive. It can be seen that the enhanced damage with the coarser abrasive can cause near-surface grain segments to be completely shattered, down to a depth of $\sim 5 \mu \mathrm{m}$ below the surface.

Fig. 14: Cross-sectional SEM image micrograph of the near-surface structure of the worn surface after the three-body wear with $3 \mu \mathrm{m}$ diamond abrasives, showing the presence of an intergranular crack. The sample was annealed at $1300^{\circ} \mathrm{C}$ prior to the wear test. 


\section{LBNL-50783}

Fig. 15: Cross-sectional SEM image micrograph of the near-surface structure of the worn surface after the three-body wear with $15 \mu \mathrm{m}$ diamond abrasives, showing that the near-surface fracture path initially involves grain boundaries and then proceeds transgranularly. The sample was annealed at $1300^{\circ} \mathrm{C}$ prior to the wear test.

Fig. 16: Schematic illustration of the sequences of events in the formation of wear debris, for (a) mild wear with fine abrasives, and (b) severe wear with coarse abrasives. Note that whereas the mechanism of wear with fine abrasives involves micro-ploughing and near-surface cracking, with coarse abrasives, intergranular cracking and grain pullout, e.g., represented by the break-out of the grain fragment in (b), are the more dominant mechanisms.

Fig. 17: Cross-sectional SEM image micrograph of the near-surface structure of the worn surface after the three-body wear with $15 \mu \mathrm{m}$ diamond abrasives, showing near-surface damage, in the form of grain segments, to be completely shattered, down to a depth of some $5 \mu \mathrm{m}$ below the surface. The sample was annealed at $800^{\circ} \mathrm{C}$ prior to the wear test.

\section{Discussion}

The major characteristic of the three- and two-body abrasive wear properties of $\mathrm{ABC}$ $\mathrm{SiC}$ studied in this work is the significant improvement in wear resistance that can be achieved by thermal annealing at, and above, $1300^{\circ} \mathrm{C}$. This increase in the wear resistance is such that $\mathrm{ABC}-\mathrm{SiC}$ has superior wear properties to commercial silicon carbide (Hexoloy $\mathrm{SA}$ ); indeed, ABC-SiC after suitable annealing displayed a wear resistance that was a factor of two or more higher than Hexaloy under identical testing conditions. However, the precise wear behavior of $\mathrm{ABC}-\mathrm{SiC}$ depends critically on the scale of the abrasive, specifically in relation to the characteristic size-scales of the microstructural changes involved. For the thermally annealed samples, depending on the temperature of the isochronal anneals, the wear resistance rose most significantly for the case of mild abrasive wear with smaller particle abrasives (less than about $20 \mu \mathrm{m}$ ), although there were certain annealing temperature regimes where the change of the wear resistance was not significant.

Remarkably, this variation in wear behavior did not correlate with any changes in indentation fracture toughness or hardness; indeed, both the later properties were essentially insensitive to the thermal annealing treatments. This at first sight may seem unusual as main materials properties that determine wear behavior are usually taken to be the hardness and (more prominently in brittle materials) the fracture toughness. However, one factor here is that the fracture toughness of $\mathrm{ABC}-\mathrm{SiC}$ is largely controlled by crack-tip 


\section{LBNL-50783}

shielding, in the form of interlocking grain bridging, in the crack wake. This is a largecrack material property that requires a crack wake of many grains to develop the full effect of the extrinsic toughening. ${ }^{2}$ It would be expected to have little relevance to the "smallcrack" cracking behavior associated with the observed wear mechanism, where conversely the cracking of both the matrix and the boundaries takes place over dimensions comparable with a single grain, or even sub-grain, size-scales.

Another striking feature of the wear behavior in $\mathrm{ABC}-\mathrm{SiC}$ is the appearance of a local maximum in wear resistance for the $1300^{\circ} \mathrm{C}$ annealing for small-particle abrasion, particularly shown by the $3 \mu \mathrm{m}$ wear data for both three- and two-body wear. This local maximum is much reduced in prominence at larger abrasive particle sizes, i.e., for $15 \mu \mathrm{m}$ abrasive and above. Since these effects are not associated with any variations in fracture toughness or hardness, the origin of these local variations in the wear behavior therefore must be associated with the microstructural evolution of $\mathrm{ABC}-\mathrm{SiC}$ during annealing; including a reduction in the processed-induced residual stresses, crystallization of the boundary films, possible changes in the grain-boundary strength, the possible healing of flaw damage, and the formation and coarsening of the nano-precipitates in $\mathrm{SiC}$ grains.

\section{(1) Mild Wear (Fine Abrasives)}

For the case of the mild abrasive wear with the fine-scale $(3 \mu \mathrm{m})$ abrasives, the wearing surface topology that develops shows microplowing, limited grain removal and associated fractures, with the actual load bearing surface remaining relatively smooth, and exhibiting microplastic wear (Figs. 11,12); similar observations of such mechanisms have been reported in refs. [17,18]. There is far less evidence of intergranular cracking here and transgranular, conchoidal cracking damage is most common mechanism that can be seen on the worn surfaces, as shown schematically in Fig. 16a. Since the affected volumes in microplowing wear of $\mathrm{SiC}$ are quite small, it can be expected that this type of wear will be affected by the matrix (rather than the boundary) properties and the presence of the nanoprecipitates, with a behavior somewhat resemble to precipitation hardening in metals and alloys. The expectation was confirmed by the fact that a good correlation exists between the formation of well dispersed, very fine precipitates and the appearance of the local wear resistance maximum after annealing at $1300^{\circ} \mathrm{C}$. However, just like the dispersion- 


\section{LBNL-50783}

hardening effect is weakened by coarsened precipitates in metals and alloys, the overaging of the precipitates in $\mathrm{ABC}-\mathrm{SiC}$ at annealing temperatures higher than $1300^{\circ} \mathrm{C}$ coarsened the nano-precipitates (Fig. 10), resulting in decline of the wear resistance from the local maximum. We thus conclude that the beneficial effect of the thermal annealing in promoting wear resistance can be attributed to reinforcement of the $\mathrm{SiC}$ grains through the formation of nano-scale precipitates with a suitable size and number density, although their coarsening may lead to a local reduction in wear resistance.

\section{(2) Severe Wear (Coarse Abrasives)}

For the severe abrasive wear associated with the coarse $(72 \mu \mathrm{m})$ abrasive, where the dimensions of the abrasive were far in excess of microstructural size-scales, the wearing surfaces looked quite different. Here grain pullout and intergranular cracking predominate, with the incidence of such damage regions being reduced with increasing annealing temperature. Grain-boundary initiated fractures and subsequent grain breakout through conchoidal cracking, Fig. 16b (with some smaller degrees of transgranular fracture and grain shattering) are main near-surface damage features (Fig. 13). Such processes are not expected to be affected by the matrix-coherent precipitates that are orders of magnitude smaller than the fracture features. Thus, in contrast to the wear mechanism in the fineparticle abrasive wear regime, the removal of material in the coarse-particle abrasive wear regime is thought to be determined more by the grain-boundary properties, and possibly by the residual stress reduction and flaw healing. The measured increase in the modulus of rupture upon annealing (Fig. 4) is perhaps an indication of the reduction in residual stresses and of possible flaw healing, although the relative increase in the modulus of rupture is significantly less than the relative increase in the wear resistance. It is therefore postulated that the increased wear resistance is associated with the strengthening of the grain boundaries, which clearly would tend to inhibit intergranular fracture. Although no conclusive evidence for such strengthening has been achieved, either experimentally or theoretically, in $\mathrm{SiC}$, as described above in section III.2 we have detected a dramatic increase (50-100 at\%) in aluminum content in the grain-boundary films after hightemperature annealing, and this effect is known to lead to grain-boundary strengthening in comparable ceramics, such as in silicon nitride. ${ }^{19}$ 


\section{LBNL-50783}

\section{Conclusions}

Based on an experimental study of the role of post-processing heat treatment on the three- and two-body abrasive wears of an in situ toughened, hot-pressed silicon carbide, $\mathrm{ABC}-\mathrm{SiC}$, using 3 to $72 \mu \mathrm{m}$ sized diamond abrasives in ambient temperature air, the following conclusions can be made:

1. Thermal annealing at $1000^{\circ}$ to $1600^{\circ} \mathrm{C}$ in argon was found to be effective in enhancing the abrasive wear resistance of $\mathrm{ABC}-\mathrm{SiC}$, almost tripling the three-body wear resistance and doubling the two-body resistance, despite the fact that the hardness and (indentation) fracture toughness remained essentially constant. In most annealed conditions, the abrasive wear resistance of $\mathrm{ABC}-\mathrm{SiC}$ was found to be a factor of two or more higher than that of commercial silicon carbide (Hexaloy SA), tested under identical conditions.

2. Microstructurally, such thermal annealing was found to result in (i) the crystallization of the grain-boundary films above $\sim 1000^{\circ} \mathrm{C}$, (ii) the matrix precipitation of aluminumrich nano-precipitates ( 1 to $5 \mathrm{~nm}$ in size) above $\sim 1300^{\circ} \mathrm{C}$, and (iii) the accumulation of aluminum in the grain boundaries, with the consequent formation of precipitatedenuded zones with low Al concentration adjacent to the grain boundaries, above $\sim 1300{ }^{\circ} \mathrm{C}$.

3. For cases of severe abrasive wear involving the coarse $(72 \mu \mathrm{m})$ abrasives, the mechanism of wear was associated with near-surface fractures, initiated primarily from grain boundaries, causing intergranular cracking and grain pullout.

4. Thermal annealing was found to diminish the incidence of such "coarse abrasive" damage and progressively improve the wear resistance with increasing annealing temperature from $\sim 1000^{\circ}$ to $1600^{\circ} \mathrm{C}$. This effect was attributed to the presumed strengthening of the boundaries due to the accumulation of aluminum there. The role of the very fine matrix precipitates was reasoned to be less important as the dimensions of the abrasive particles were far in excess of those of the nano-precipitates. 


\section{LBNL-50783}

5. For cases of mild abrasive wear involving the fine $(3 \mu \mathrm{m})$ abrasives, the mechanism of wear was associated primarily with micro-ploughing and mostly transgranular nearsurface crack formation (conchoidal cracking damage), with only limited incidence of intergranular cracking and grain pullout.

6. The effect of thermal annealing was more complex in affecting such mild abrasive wear properties. In general, thermal annealing led to an improvement in the wear resistance of $\mathrm{ABC}-\mathrm{SiC}$, an effect likely associated with the local matrix strengthening from the presence of the nano-precipitates. However, with higher temperature annealing, the consequent coarsening of these precipitates led to degradation in the wear properties, approaching that of the as-hot pressed microstructure.

\section{Acknowledgments}

This work was supported by the Director, Office of Science, Office of Basic Energy Sciences, Division of Materials Sciences and Engineering of the U.S. Department of Energy under Contract No. DE-AC03-76SF0098. Part of this work was made possible through the use of the National Center for Electron Microscopy facility at the Lawrence Berkeley National Laboratory. Thanks are due to Qing Yang for her help in processing the $\mathrm{SiC}$ samples. 
Table 1: Indentation hardness $(H)$, indentation fracture toughness $\left(K_{I c}\right)$, and flexural strength $\left(\sigma_{\mathrm{f}}\right)$ for $\mathrm{ABC}-\mathrm{SiC}$ without and with annealing in Ar for $72 \mathrm{hrs}$.

\begin{tabular}{llll}
\hline Samples & $\boldsymbol{H}^{\mathbf{a}}$ & $\begin{array}{l}\boldsymbol{K}_{\boldsymbol{I c}}^{\mathbf{b}} \\
\left(\mathrm{MPa} \mathrm{m}{ }^{1 / 2}\right)\end{array}$ & $\begin{array}{l}\sigma_{\mathbf{f}} \\
(\mathrm{MPa})\end{array}$ \\
\hline ABC-SiC & $(\mathrm{GPa})$ & $-5.33 \pm 0.26$ & $515 \pm 15$ \\
\hline As-processed & $25.2 \pm 1.6$ & - & $511 \pm 40$ \\
$700^{\circ} \mathrm{C}$ & - & $5.28 \pm 0.32$ & $460 \pm 34$ \\
$1000^{\circ} \mathrm{C}$ & $24.9 \pm 1.8$ & $5.31 \pm 0.34$ & $447 \pm 29$ \\
$1200^{\circ} \mathrm{C}$ & $25.7 \pm 1.6$ & $5.44 \pm 0.31$ & $604 \pm 17$ \\
$1300^{\circ} \mathrm{C}$ & $25.2 \pm 2.4$ & $5.37 \pm 0.26$ & - \\
$1400^{\circ} \mathrm{C}$ & $26.5 \pm 1.7$ & $5.39 \pm 0.25$ & $685 \pm 20$ \\
$1500^{\circ} \mathrm{C}$ & $26.0 \pm 2.2$ & & \\
\hline
\end{tabular}

${ }^{\text {a } L o w-l o a d ~ V i c k e r s ~ m i c r o h a r d n e s s, ~ u s i n g ~ a n ~ i n d e n t a t i o n ~ l o a d ~ o f ~} 4.9 \mathrm{~N}$.

${ }^{b}$ Vickers indentation fracture toughness, using an indentation load of $78.4 \mathrm{~N}$. 


\section{LBNL-50783}

Table 2: Experimentally measured data for the plate-like nanoscale precipitates formed in the annealed ABC-SiC. Statistical mean values and standard deviations are listed

\begin{tabular}{|c|c|c|c|c|}
\hline \multirow[t]{2}{*}{ Nano-Precipitates } & \multicolumn{4}{|c|}{ Annealing Temperature (ABC-SiC) } \\
\hline & $1300^{\circ} \mathrm{C}$ & $1400^{\circ} \mathrm{C}$ & $1500^{\circ} \mathrm{C}$ & $1600^{\circ} \mathrm{C}$ \\
\hline Length (nm) & $4.6 \pm 0.9$ & $9.8 \pm 0.3$ & $11.8 \pm 2.4$ & $21.1 \pm 7.6$ \\
\hline Thickness (nm) & $1.2 \pm 0.1$ & $3.9 \pm 1.3$ & $4.0 \pm 1.2$ & $5.5 \pm 1.4$ \\
\hline Aspect Ratio & $3.8 \pm 1.2$ & $2.7 \pm 1.0$ & $3.1 \pm 1.0$ & $4.0 \pm 1.6$ \\
\hline Separation (nm) & $6.4 \pm 3.6$ & $17.9 \pm 5.6$ & $19.8 \pm 7.9$ & $38.6 \pm 16.4$ \\
\hline Volume $\left(\mathrm{nm}^{3}\right)$ & 16 & 300 & 428 & 2200 \\
\hline Number Density $\left(1 / \mathrm{m}^{3}\right)$ & $5 \times 10^{22}$ & $1 \times 10^{22}$ & $7 \times 10^{21}$ & $2 \times 10^{21}$ \\
\hline Volume Fraction* & $0.8 \times 10^{-3}$ & $3.0 \times 10^{-3}$ & $3.0 \times 10^{-3}$ & $4.4 \times 10^{-3}$ \\
\hline
\end{tabular}

$*$ Volume fraction $=$ Mean Volume $\times$ Number Density 


\section{LBNL-50783}

\section{References}

${ }^{1}$ J. J. Cao, W. J. MoberlyChan, L. C. De Jonghe, C. J. Gilbert, and R. O. Ritchie, “In situ toughened silicon carbide with Al-B-C additions," J. Am. Ceram. Soc., 79 [2] 461-69 (1996).

${ }^{2}$ C. J. Gilbert, J. J. Cao, L.C. De Jonghe, and R. O. Ritchie, "Crack-growth resistancecurve behavior in silicon carbide: small versus long cracks," J. Am. Ceram. Soc., 80 [9] 2253-61 (1997).

${ }^{3}$ W. J. MoberlyChan, J. J. Cao, C. J. Gilbert, R. O. Ritchie, and L. C. De Jonghe, "The cubic-to-hexagonal transformation to toughen $\mathrm{SiC}$," pp. 177-90 in Ceramic Microstructure: Control at the Atomic Level, edited by A.P. Tomsia and A. Glaeser, Plenum Press, New York, 1998.

${ }^{4}$ P. F. Becher, E. Y. Sun, K.P. Plucknett, K. B. Alexander, C. H. Hsueh, H. T. Lin, S. B. Waters, and C. G. Westmoreland, "Microstructural design of silicon nitride with improved fracture toughness: I. effects of grain shape and size," J. Am. Ceram. Soc., 81 [11] 2821-30 (1998).

${ }^{5}$ H. J. Kleebe, M. K. Cinibulk, R. M. Cannon, and M. Rühle, "Statistical analysis of the intergranular film thickness in silicon nitride ceramics", J. Am. Ceram. Soc., 76 [8] 196977 (1993).

${ }^{6}$ Y. M. Chiang, L. A. Silverman, R. H. French, and R. M. Cannon, "Thin glass film between ultrafine conductor particles in thick-film resistors," J. Am. Ceram. Soc., 77 [5] 1143-52 (1994).

${ }^{7}$ Q. Jin, X. G. Ning, D. S. Wilkinson, and G. C. Weatherly, "Redistribution of a grainboundary glass phase during creep of silicon nitride ceramics," J. Am. Ceram. Soc., 80 [3] 685-91 (1997).

${ }^{8}$ Q. Jin, D. S. Wilkinson, and G. C. Weatherly, "High-resolution electron microscopy investigation of viscous flow creep in a high-purity silicon nitride," J. Am. Ceram. Soc., 82 [6] 1492-96 (1999).

${ }^{9}$ X. F. Zhang, M. E. Sixta, and L. C. De Jonghe, "Grain boundary evolution in hotpressed ABC-SiC,” J. Am. Ceram. Soc., 83 [11] 2813-20 (2000).

${ }^{10}$ X. F. Zhang, M. E. Sixta, and L. C. De Jonghe, "Diffusion-controlled responses to heat treatment of toughened silicon carbide", Defect and Diffusion Forum, 186-187 45-60 (2000).

${ }^{11}$ X. F. Zhang, M. E. Sixta, and L. C. De Jonghe, "Nano-precipitation in hot-pressed silicon carbide," J. Mater. Sci., 36 5447-55 (2001). 


\section{LBNL-50783}

${ }^{12}$ T. Senda, E. Yasuda, M. Kaji, and R. C. Bradt, "Effect of grain size on the sliding wear and friction of alumina at elevated temperatures," J. Am. Ceram. Soc., 82 [6] 1505-11 (1999).

${ }^{13}$ B. Lawn, N. P. Padture, H. Cai, and F. Guiberteau, "Making ceramics ductile," Science 263 [2] 1114-16 (1994).

${ }^{14}$ X. F. Zhang, M. E. Sixta, and L. C. De Jonghe, "Secondary phases in hot-pressed ABC-silicon carbide," J. Am. Ceram. Soc., 84 [4] 813-20 (2001).

${ }^{15} \mathrm{P}$. H. Shipway, "The role of test conditions on the microabrasive wear behaviour of soda-lime glass", Wear, 233-235 191-99 (1999).

${ }^{16}$ M.-O. Guillou, J. L. Henshall, and R. M. Hooper, "The measurement of surface contact fatigue and its application to engineering ceramics," Mat. Sci. Eng. A, 209 116-27 (1996).

${ }^{17}$ B. J. Hockey, "Plastic deformation of aluminum oxide by indentation and abrasion," J. Am. Ceram. Soc., 54 [5] 223-31 (1971).

${ }^{18}$ J. T. Czernuszka, and T. F. Page, "Characterizing the surface contact behavior of ceramics, Part 2. chemo-mechanical effects,” J. Mater. Sci., 22 3917-23 (1987).

${ }^{19}$ G.S. Painter, P.F. Becher, and E.Y. Sun, "Bond energetics at intergranular interfaces in alumina-doped silicon nitride," J. Am. Ceram. Soc., 85 [1] 65-7 (2002). 


\section{LBNL-50783}

\section{List of Figure Captions:}

Fig. 1: Schematic illustrations of the tribological setups for (a) the three-, and (b) the two-body wear tests.

Fig. 2: Cross-sectional SEM micrograph showing the original surface prior to wear, indicating that the sectioning and polishing does not introduce significant nearsurface damage.

Fig. 3: Schematic illustration of the procedure employed in preparation of crosssectional SEM samples to study subsurface wear damage.

Fig. 4: Experimentally measured variation in indentation hardness, indentation toughness $\left(K_{I C}\right)$, and flexural strength $\left(\sigma_{\mathrm{f}}\right)$ of ABC-SiC samples as a function of the annealing temperature between $800^{\circ}$ and $1600^{\circ} \mathrm{C}$.

Fig. 5: Experimentally measured variation in three-body and two-body wear resistance $\left(1 / K_{\mathrm{w}}\right)$ as a function of the annealing temperature, using a $3 \mu \mathrm{m}$ diamond abrasive.

Fig. 6: Experimentally measured variation in three-body and two-body wear resistance $\left(1 / K_{\mathrm{w}}\right)$ as a function of the annealing temperature, using a $15 \mu \mathrm{m}$ diamond abrasive.

Fig. 7: Experimentally measured variation in two-body wear resistance $\left(1 / K_{\mathrm{w}}\right)$ as a function of the annealing temperature, using a $72 \mu \mathrm{m}$ diamond abrasive.

Fig. 8: Scanning electron micrograph of the plasma-etched, as-hot-pressed microstructure of $\mathrm{ABC}-\mathrm{SiC}$.

Fig. 9: TEM micrographs showing the transformation of the amorphous grain boundary film (a) to a crystallized film (b) after thermal annealing at $1000^{\circ} \mathrm{C}$ for $5 \mathrm{hrs}$. The grain boundaries shown in (a) and (b) are not the same one.

Fig. 10: TEM micrographs showing in-grain nano-precipitates in $\mathrm{SiC}$ annealed at $1300^{\circ}, 1400^{\circ}, 1500^{\circ}$, and $1600^{\circ} \mathrm{C}$, respectively. Note the coarsening in size accompanied by number reduction of the precipitates with increasing annealing temperature.

Fig. 11: SEM images of the morphologies of the worn surfaces after the two-body abrasive wear with $3 \mu \mathrm{m}$ diamond abrasives, showing (a) an overall image and high magnification details of the light-contrast pits $(b, c)$ which demonstrate transgranular, conchoidal fracture. The images were obtained from an as-hotpressed sample.

Fig. 12: SEM images showing the morphologies of the worn surfaces after the twobody abrasive wear with $3 \mu \mathrm{m}$ diamond abrasives, showing (a) as-hot-pressed 


\section{LBNL-50783}

$\mathrm{ABC}-\mathrm{SiC}$, and (b) following $1300^{\circ} \mathrm{C}$ annealing, showing reduction in pitting due to the annealing.

Fig. 13: SEM images showing the morphologies of the worn surfaces after the twobody abrasive wear with $72 \mu \mathrm{m}$ diamond abrasives. The image in (a) was obtained from the as-hot-pressed $\mathrm{ABC}-\mathrm{SiC}$, and that in (b) was from the sample after $1300^{\circ} \mathrm{C}$ annealing.

Fig. 14: Cross-sectional SEM image micrograph of the near-surface structure of the worn surface after the three-body wear with $3 \mu \mathrm{m}$ diamond abrasives, showing the presence of an intergranular crack. The sample was annealed at $1300^{\circ} \mathrm{C}$ prior to the wear test.

Fig. 15: Cross-sectional SEM image micrograph of the near-surface structure of the worn surface after the three-body wear with $15 \mu \mathrm{m}$ diamond abrasives, showing that the near-surface fracture path initially involves grain boundaries and then proceeds transgranularly. The sample was annealed at $1300^{\circ} \mathrm{C}$ prior to the wear test.

Fig. 16: Schematic illustration of the sequences of events in the formation of wear debris, for (a) mild wear with fine abrasives, and (b) severe wear with coarse abrasives. Note that whereas the mechanism of wear with fine abrasives involves micro-ploughing and near-surface cracking, with coarse abrasives, intergranular cracking and grain pullout, e.g., represented by the break-out of the grain fragment in (b), are the more dominant mechanisms.

Fig. 17: Cross-sectional SEM image micrograph of the near-surface structure of the worn surface after the three-body wear with $15 \mu \mathrm{m}$ diamond abrasives, showing near-surface damage, in the form of grain segments, to be completely shattered, down to a depth of some $5 \mu \mathrm{m}$ below the surface. The sample was annealed at $800^{\circ} \mathrm{C}$ prior to the wear test. 